\title{
Clinical and molecular features of one case of human infection with Anaplasma phagocytophilum from Podlaskie Province in eastern Poland
}

\author{
Renata Welc-Falęciak' ${ }^{1}$, Maciej Kowalec ${ }^{1}$, Joanna Zajkowska², Sławomir A Pancewicz², \\ Edward Siński ${ }^{1}$ \\ ${ }^{1}$ Department of Parasitology, University of Warsaw, Poland \\ ${ }^{2}$ Department of Infectious Diseases and Neuroinfections, Medical University, Białystok, Poland
}

Welc-Falęciak R, Kowalec M, Zajkowska J, Pancewicz SA, Siński E. Clinical and molecular features of one case of human infection with Anaplasma phagocytophilum from Podlaskie Province in eastern Poland. Ann Agric Environ Med. 2015; 22(3): 414-417. doi: 10.5604/12321966.1167704

\begin{abstract}
The article focuses on the clinical and laboratory diagnosis of human granulocytic anaplasmosis (HGA) caused by Anaplasma phagocytophilum infection in one of 28 patients (3.6\%; $n=1 / 28$ tested samples) with early Lyme borreliosis. The clinical and laboratory results of a 42-year-old patient fulfilled criteria of confirm anaplasmosis and suggest an acute stage of illness. The described case provides strong presumptive evidence that infection in this patient was acquired with a pathogenic strain of $A$. phagocytophilum through a tick bite. A positive DNA with PCR for A. phagocytophilum infection was sequenced and analyzed phylogenetically. Physicians should consider the possibility of anaplasmosis in patients with early Lyme borreliosis, and $A$. phagocytophilum should be considered as a differential diagnosis in all patients from an endemic region of potential high risk factors for tick-borne diseases.
\end{abstract}

Key words

Anaplasma phagocytophilum, anaplasmosis, coinfection, Lyme borreliosis, clinical and molecular diagnosis

\section{INTRODUCTION}

Anaplasma phagocytophilum is a gram-negative, obligate intracellular bacterium that has tropism for neutrophils and causes a tick-borne rickettsial disease, known as human granulocytic anaplasmosis (HGA), formerly human granulocytic ehrlichiosis [1]. HGA is an emerging zoonosis worldwide and recently recognized as an important and frequent tick-borne disease in USA and in many parts of Europe and Asia. The clinical symptoms of HGA range from asymptomatic seroconversion to mild, severe, or fatal disease [1]. In the north-east of Poland, an endemic region for tickborne encephalitis, Lyme borreliosis (LB), babesiosis, the epidemiology of HGA, especially in the inhabitants of rural areas with increased possibility of contact with the vector Ixodes ricinus, is still poorly recognized. The first three cases of acute human HGA in this part of Poland were identified by an indirect immunofluorescence assay and confirmed using PCR [2]. Although in Poland the seroprevalence of HGA in 'high risk' groups, mostly forestry workers, has been assessed in a few prospective studies $[3,4,5]$. Also, in a Borrelia-seropositive person from southeastern Poland, co-infection was shown with $A$. phagocytophilum and Babesia spp. [6]. However, in some countries of Europe, from relatively high seroprevalence of HGA (from 32\% in Cyprus to $8.8 \%$ in Italy) to low (1.3\% in the Netherlands) the cases were revealed mostly in forestry workers $[7,8$, 9]. In Europe, populations of I. ricinus, the main vector of

Address for correspondence: Renata Welc-Falęciak, Department of Parasitology Faculty of Biology, University of Warsaw, Miecznikowa 1, 02-096 Warsaw, Poland E-mail: rwelc@biol.uw.edu.pl

Received: 20 October 2013; accepted: 05 June 2014
A. phagocytophilum from the zoonotic reservoir, are infected to a variable extent, approximately from $4 \%-67 \%$ [10]. Quite recently, the presence of a strain or genetic variants of A. phagocytophilum pathogenic for humans and animal zoonotic reservoirs has been revealed in I. ricinus ticks and roe deer populations in from Poland [11]. To-date, a few cases of infection with A. phagocytophilum through blood transfusion have been reported [12], as well as sporadic cases of nosocomial and perinatal transmission $[13,14]$.

The presented study investigates the clinical, molecular and phylogenetic features of $A$. phagocytophilum for inpatients and outpatients at the Department of Infectious Diseases and Neuroinfections at the Medical University of Białystok, with early LB and due to clinical findings suspected for HGA.

\section{MATERIALS AND METHOD}

Retrospectively, in 2011, blood samples were taken from 28 patients -16 males and 12 females, mean age 45.2 years (ranges 18-75) during outpatient hospitalizations for tick-borne diseases (TBDs) at the Department of Infectious Diseases and Neuroinfections at the Medical University in Białystok, and examined for the presence of $A$. phagocytophilum specific DNA in co-infection with LB. The diagnosis of early LB was based on erythema migrans and other clinical judgments. Two $\mathrm{ml}$ of whole blood were collected into 0.001M EDTA and stored at $-20^{\circ} \mathrm{C}$ until a retrospective analysis could be performed.

Molecular detection of $A$. phagocytophilum. DNA isolation and PCR analysis. The genomic DNA was extracted from 
whole blood using DNAeasy Blood and Tissue Kit (Qiagen, Crawley, UK) and stored at $-20^{\circ} \mathrm{C}$. Detection and genotyping of A.phagocytophilum were performed by amplification and sequencing of two loci. For this, two sets of primers, for the groESL heat shock operon [15], and 16S rRNA gene [16] for A. phagocytophilum were applied. Reactions were performed in a final volume of $20 \mu \mathrm{l}$ and contained $0.33 \mathrm{mM}$ dNTPs (Eurobio, Lille, France), $2 \mathrm{mM} \mathrm{MgCl}, 1 \times$ PCR buffer, $1 \mathrm{U}$ Taq polymerase (Fermentas), $1 \mu \mathrm{M}$ of each primer and $5 \mu \mathrm{l}$ of extracted DNA sample. A. phagocytophilum DNA extracted from roe deer blood was used as positive controls. Negative controls were performed in the absence of template DNA. Amplicons were visualized with Midori Green stain (Nippon Genetics Europe $\mathrm{GmbH}$ ) following electrophoresis in 2\% agarose gels. Amplicons were purified using the Axygen Clean-up purification kit (Axygen, USA) and sequenced by a private company (Genomed S.A., Poland) in both directions.

Phylogenetic characterization of A. phagocytophilum. DNA sequence alignments and phylogenetic analysis were conducted using MEGA version 5.0. After testing the data for the best substitution model, phylogenetic trees were obtained using Maximum Likelihood as the tree construction method and Tamura-Nei model parameter algorithm as a distance method. For comparison, sequences of $A$. phagocytophilum strains obtained from GenBank (www.ncbi.nlm.nih.gov) were implemented in the sequence alignment. The stability of inferred phylogenies was assessed by bootstrap analysis of 1,000 randomly generated sample trees.

Nucleotide sequence accession numbers. New nucleotide sequences were deposited in GenBank with Accession No. KF111754 for 16S rRNA gene, and Accession No. KF015601 for groESL (a heat-shock protein) gene.

\section{RESULTS}

Case clinical history. Among 28 patients with early LB, one was infected with A. phagocytophilum. The patient, aged 42, was admitted to hospital because of malaise, general muscles pain and weakness 10 days after removing the tick from the right leg; bruising and erythema with a diameter of about $10 \mathrm{~cm}$ appeared at the site. Erythematous changes in the right lower leg with swollen, ankle was stated. The patient was limping because of the pain in the limb. Erythema is likely to respond with suspected LB. The married patient does not work because he is a pensioner, takes antidepressants (lerivon, neurotop, anafranil), and smokes 1-2 packs of cigarettes a day.

Results of laboratory tests performed on admission: SR 2/6, ALAT $68 \mathrm{U} / \mathrm{l}$, AspAT $74 \mathrm{U} / \mathrm{ml}$, cholesterol $216 \mathrm{mg} / \mathrm{dl}$, blood pressure 140/100, ECG: regular sinus rhytm 77/min. Morphology: WBC-5.84, RBC 4.72, Hgb15.6 g/dl, Hct 46,5\%, MCV 98.5 fl, MCH 33.1pg MCHC $33.5 \mathrm{~g} / \mathrm{dl}$, plt 170. Antibodies against LB were negative in both classes (IgM 3 BBU/ml, IgG $2 \mathrm{BBU} / \mathrm{ml}$, Biomedica, Germany).

Treatment. Due to the presence of erythema corresponding EM, the patient initially received ceftriaxon ( $2 \mathrm{~g} /$ day) followed by amoxicillin $(3 \times 500 /$ day $)$ for a further two weeks. Erythema faded without a trace after a few days and the patient's condition improved. After completing 24-days therapy, follow-up visits in the Outpatient Clinic revealed no complaints, and no changes in physical evaluation were stated.

After one year, during the next follow-up visit, the patient presented with a general good condition and no complaints. No pathology revealed in physical examination. Antibodies against LB were negative in both classes (IgM 3 BBU/ml, IgG $1 \mathrm{BBU} / \mathrm{ml}$ (Biomedica, Germany), ALAT $24 \mathrm{U} / \mathrm{ml}$, AspAT-22 $\mathrm{U} / \mathrm{ml}$, cholesterol $235 \mathrm{mg} / \mathrm{dl}$, CRP 1.8. The serological result for anaplasmosis in the IFA was negative with IgG antibodies titer less than 64.

Molecular feature and phylogenetic analysis of $A$. phagocytophilum. A. phagocytophilum DNA was detected in one blood sample ( $3.6 \%, n=1 / 28$ tested samples) (Fig. 1). The $540 \mathrm{bp}$ fragment of the $16 \mathrm{~S}$ rRNA gene and the $1200 \mathrm{bp}$

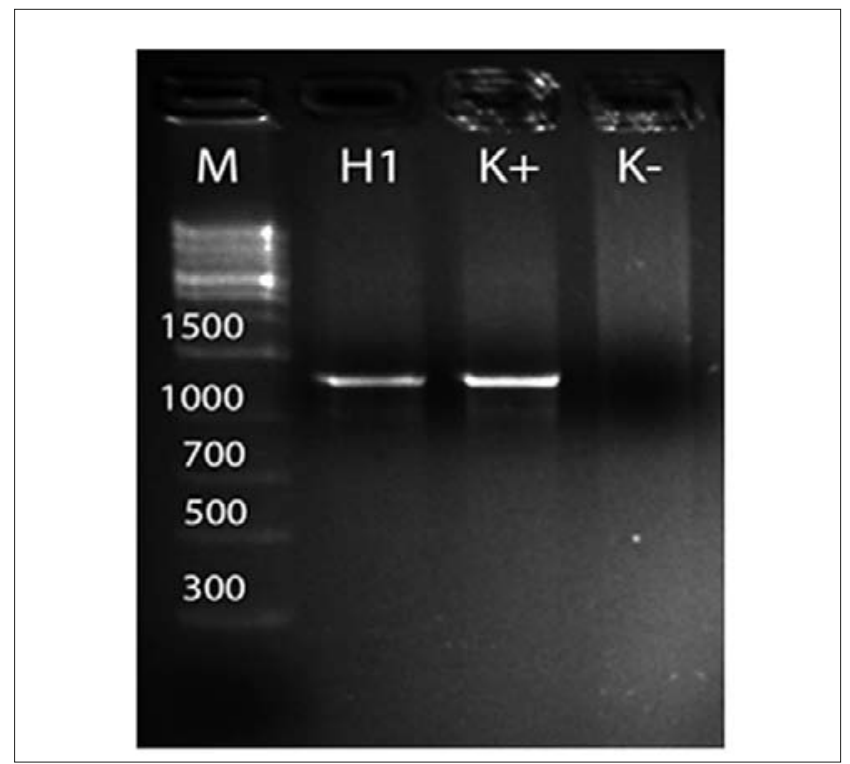

Figure 1. Anaplasma phagocytophilum heat shock operon fragment amplified from DNA extracted from blood of studied patient, analyzed by $2 \%$ agarose gel electrophoresis ( $\mathrm{M}$ - size marker; $\mathrm{H} 1$ - human sample; $\mathrm{K}(+)$ - positive control; $\mathrm{K}(-)$ - negative control)

fragment of the groESL heat shock operon were further analyzed for one isolate. Sequencing analysis of the PCR products using both sets of primers showed $100 \%$ homology with A. phagocytophilum strains pathogenic for humans (16S rRNA:AF189153; groESL: AF033101) and animals (16S rRNA:EU839852, AF507941; groESL: EU381150, AF482760). Scrutiny of the phylogenetic tree, based on the partial groESL operon sequences, confirmed that the presented human isolate clustered with $A$. phagocytophilum pathogenic for human and domestic animals in Europe and in North America (Fig. 2). Thus, this variant is considered to represent zoonotic genotypes.

\section{DISCUSSION}

The causative agent of HGA known as A. phagocytophilum (previously described as $A$. phagocytophila) belongs to the order Rickettsiales, family Anaplasmataceae [10]. In Europe, HGA remains a rare disease, compared with the USA, and in infected persons who are symptomatic, illness onset occurs 5-21 days after a tick bite. Typical symptoms include 


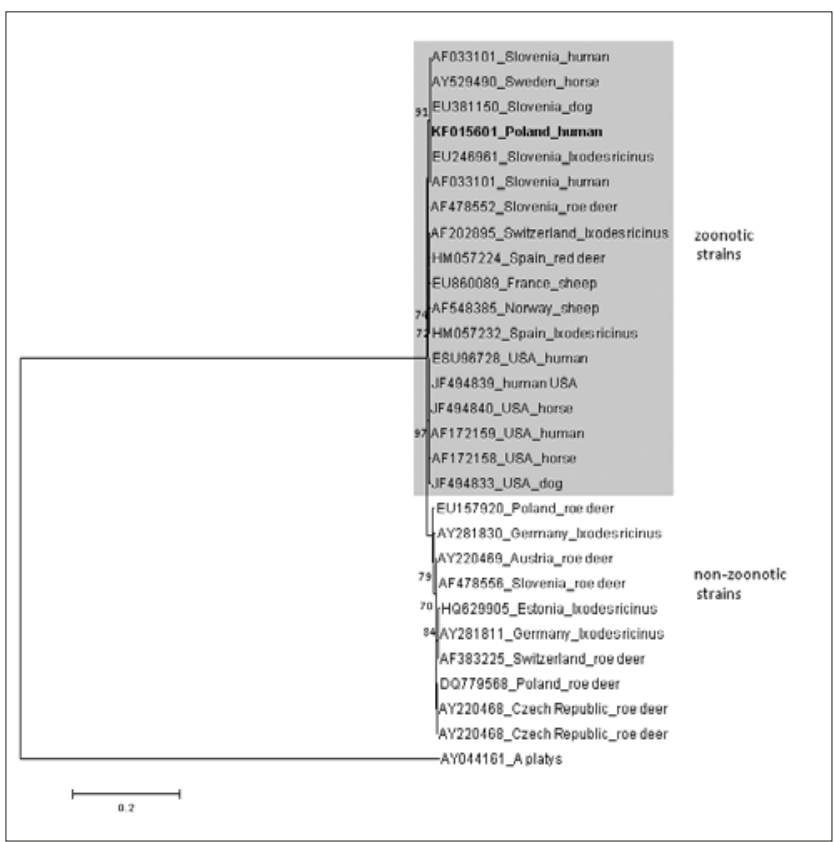

Figure 2. Phylogenetic tree of the A. phagocytophilum isolate studied in the current work and selected isolates from GenBank based on the fragment of the groESL heat shock operon. Numbers at the nodes of the tree indicate bootstrap values ( 1,000 replicates, only bootstrap values $>70 \%$ are shown). The nucleotide sequence of $A$. platys was used as an outgroup. The isolate in this study is marked in bold

sudden onset of fever, headache, malaise, and myalgia, often accompanied by thrombocytopenia, leukopenia, and elevated liver transaminases. Severe infections can include prolonged fever, shock, confusion, seizures, pneumonitis, renal failure, haemorrhages, opportunistic infections, and death [17].

Serological immune response against $B$. burgdorferi is maintained for several years among immune competent patients after successful treatment, and both IgG and IgM antibody titers fall slowly [18]. A negative result strongly suggests exclusion of the diagnosis of Lyme disease, as in the presented case. Serological testing against anaplasmosis has adifferent pattern and disappears fast; thus, a negative result after one year is not conclusive for diagnosis.

The current study reports the patient's clinical history and the laboratory investigations of a mild course of anaplasmosism, as well as the molecular and phylogenetic analysis of $A$. phagocytophilum in a 42 -year-old male patient. The clinical and laboratory results fulfilled the criteria for confirmation of anaplasmosis, and suggested an acute stage of the illness. The patient had slightly elevated levels of some laboratory parameters, e.g. ALAT, AspAT and cholesterol. It is well documented that cholesterol levels tend to increase with increasing age [19]. On the other hand, some authors point out that more sever anaplasmosis should be associated with increased age. For example, in the USA, 51 years of age has been confirmed as the median age for anaplasmosis, and stresses that the median age with other TBD is much lower, e.g. for patient with LB - 39 years of age [20].

Analysis of the A. phagocytophilum genome sequences revealed that these bacteria infecting granulocytes are lacking all genes for the biosyntesis of lipid A, and most genes for the biosynthesis of peptidoglycan which confer structural strength to these bacteria. Thus, these bacteria incorporate exogenous cholesterol and become cholesterol dependent due to the loss of these genes; the dependency of A. phagocytophilum on cholesterol may partially correlate with age [21]. Also, there is experimental data on the mice model that high blood cholesterol levels resulting from an interaction between dietary and genetic factors, facilitate $A$. phagocytophilum infection and up-regulate a proinflamatory chemokine and its receptor, which may contribute to HGA pathogenesis [22].

The described case provides strong presumptive evidence that infection in this patient was acquired with a pathogenic strain/ variant of $A$. phagocytophilum through a tick bite, as proved by molecular and phylogenetic analyses. A. phagocytophilum strains have been characterized using a variety of genetic markers, including the genes encoding the small-subunit rRNA (16S rRNA), a heat-shock protein (groESL), the major surface proteins $(m s p)$ and the AnkA protein $(a n k A)$. Although the $16 S$ rRNA and groESL genes demonstrate a minor degree of variation in their nucleotide sequences, several genetic variants have been detected in sequences derived from different mammalian hosts, ticks, and geographical regions [23]. In the current case, amplification of partial sequences from the $16 \mathrm{~S}$ rRNA and groESL gens, DNA sequencing and phylogenetic analysis provided reliable evidence of anaplasmosis due to the human strain of $A$. phagocytophilum. It is well known that the zoonotic pathogen of $A$. phagocytophilum has a high degree of biological and clinical diversity; some of strains/variants are pathogenic in both humans and animals, while others only for animals $[11,24]$.

In the forested areas of eastern Poland, infections of A. phagocytophilum transmitted by the I. ricinus were previously reported in foresters with an approximate prevalence of $10 \%[2,3,25]$. Patients who develop post-ticks bite non-specific fever, accompanied by acute thrombocytopenia and high level of cholesterol, should be evaluated by clinical examination and routine laboratory testing to determine if the illness is potentially a A. phagocytophilum infection, especially in co-infection with LB.

\section{Acknowledgements}

This research is part of Project No. NN 404795240 supported by the Ministry of Science and Higher Education in Warsaw, Poland.

\section{REFERENCES}

1. Dumler JS, Choi K-S, Garcia-Garcia JC, Barat NS, Scorpio DG, Garyu JW, Grab DJ, Bakken JS. Human granulocytic anaplasmosis and Anaplasma phagocytophilum. Emerg Infect Dis. 2005; 11: 1828-1834.

2. Tylewska-Wierzbanowska S, Chmielewski T, Kondrusik M, Hermanowska-Szpakowicz T, Sawicki W, Sułek K. First cases of acute human granulocytic ehrlichiosis in Poland. Eur J Clin Microbiol Infect Dis. 2001; 20: 196-198.

3. Grzeszczuk A, Stanczak J, Kubica-Biernat B, Racewicz, KruminisLozowska W, et al. Human anaplasmosis in north-estern Poland: seroprevalence in humans and prevalence in Ixodes ricinus ticks. Ann Agric Environ Med. 2004; 11: 99-103.

4. Cisak E, Chmielewska-Badora J, Zwolinski J, Wojcik-Fatla A, Polak J, Dutkiewicz J. Risk of tick-borne bacterial diseases among workers of Roztocze National Park (south-eastern Poland). Ann Agric Environ Med. 2005; 12: 127-132.

5. Chmielewska-Badora J, Moniuszko A, Zukiewicz-Sobczak W, Zwolinski J, Piątek J, et al. Serological survey in persons occupationally expose to tick-borne pathogens in cases of co-infection with Borrelia burgdorferi, Anaplasma phagocytophilum, Bartonella spp. and Babesia microti. Ann Agric Environ Med. 2012; 19: 271-274.

6. Welc-Falęciak R, Hildebrandt A, Siński E. Co-infection with Borrelia species and other tick-borne pathogens in humans: two cases from Poland. Ann Agric Environ Med. 2010;17: 309-313. 
7. Chochlakis D, Koliou M, Ioannou I, Tselentis Y, Psaroulaki A. Kawasaki diseases and Anaplasma sp. infection in an infant, in Cyprus. Int J Infect Dis. 2009; 13: e71-e73.

8. Cinco M, Barbone F, Grazia Ciufolini M, Mascioli M, Anguero Rosenfeld M, Stefanel P, et al. Seroprevalence of tick-borne infections in forestry rangers from northeastern Italy. Clin Microbiol Infect. 2004; 10: 1056-1061.

9. Groen J, Koraka P, Nur YA, Avsic-Zupanc T, Goessens WH, Ott A, et al. Serologic evidence of ehrlichiosis among humans and wild animals in the Netherlands. Eur J Clin Microbiol Infect Dis. 2002; 21: 46-49.

10. Blanco JR, Oteo JA. Human granulocytic ehelichiosis in Europe. Clin Microbiol Infect. 2002; 8: 763-772.

11. Welc-Falęciak R, Werszko J, Cydzik K, Bajer A, Michalik J, Behnke JM. Co-infection and genetic diversity of tick-borne pathogens in roe deer from Poland. Vector-Borne Zoonotic Dis. 2013; 13: 277-288.

12. Jereb M, Pecaver B, Tomazic J, Muzlovic I, Avsic-Zupanc T, PremruSrsen T, Levicnik-Stezinar S, Karner P, Strle F. Severe human granulocytic anaplasmosis transmitted by blood transfusion. Emerg Infect Dis. 2012; 18: 1354-1357.

13. Zhang L, LiuY, Ni D, Li Q, Yu Y, Yu KY, et al. Nosocomial transmission of human granulocytic anaplasmosis in China. JAMA. 2008; 300: 2263-2270.

14. Horowitz HW, Kilchevsky E, Haber S, Aguero-Rosenfeld M, Krawinkel $\mathrm{R}$, James EK, et. al. Peritonal transmission of the agent of the human granulocytic ehrlichiosis. N Eng J Med. 1998; 339: 375-378.

15. Sumner JW, Nicholson WL, Massung RF. PCR amplification and comparison of nucleotide sequences from the groESL heat shock operon of Ehrlichia species. J Clin Microbiol. 1997; 35: 2087-2092.

16. Massung RF, Slater K, Owens JH, Nicholson WL, et al. Nested PCR assay for detection of granulocytic ehrlichiae. J Clin Microbiol. 1998; 36: 1090-1095.
17. CDC. Diagnosis and management of tickborne rickettsial diseases: Rocky Mountain spotted fever, ehrlichiosis, and anaplasmosis - United State. Morbidity and Mortality Weekly Report (MMWR). 2006; RR-4.

18. Kalish RA, McHugh G, Granquist J, Shea B, Ruthazer R, Steere AC. Persistence of IgM or IgG antibody responses to Borrelia burgdorferi 10 to 20 years after active Lyme disease. Clin Infect Dis. 2001; 33: 780-785.

19. Chung SJ. Relationship among age, serum cholesterol level and population percentile in adults. Int J Bio-Med Comput. 1992; 31: 99-116.

20. Gardner SL, Holman RC, Krebs JW, Berkelman R, Childs JE. National surveillance for the human ehrlichioses in the United States, 1997-2001, and proposed methods for evaluation of quality. Ann N Y Acad Sci. 2003; 990: 80-89.

21. Lin M, Rikihisa Y. Ehrlichia chaffeensis and Anaplasma phagocytophilum lack genes for lipid A biosynthesis and incorporate cholesterol for their survival. Infect Immun. 2003; 71: 5324-5331.

22. Xiong Q, Wang X, Rikihisa Y. High-choresterol diet facilitates Anaplasma phagocytophilum infection and up-regulates macrophage inflammatory protein-2 and CXCR2 expresion in apolipoprotein E-deficient mice. J Infect Dis. 2007; 195: 1497-1503.

23. Katargina O, Geller J, Alekseev A, Dubinina H, Efremova G, Mishaeva N, et al. Identification of Anaplasma phagocytophilum in tick populations in Estonia, European Part of Russia and Belarus. Clin Microbiol Infect. 2012; 18: 40-46

24. Massung RF, Courtney JW, Hiratzka SL, Pitzer VE, Smith G, Dryden RL. Anaplasma phagocytophlum in white-tailed deer. Emerg Infect Dis. 2005; 1: 1604-1606.

25. Grzeszczuk A. Anaplasma phagocytophilum in Ixodes ricinus ticks and human granulocytic anaplasmosis seroprivalence among forestry rangers in Bialystok region. Adv Med Sci. 2006; 51: 283-286. 